\title{
Acute onset of Lupus associated Pancreatitis Mimicking Pancreatic Cancer
}

\section{Marco Ardesia ${ }^{1}$, Marcello Cintolo $^{2}$, Stefano Crinò ${ }^{3}$, Paolo Todaro ${ }^{4}$, Giuseppe Speciale ${ }^{4}$, Walter Fries ${ }^{2^{\star}}$}

${ }^{1}$ Internal Medicine, ${ }^{2}$ Clinical Unit for Chronic Bowel Disorders, ${ }^{3}$ Endoscopy Unit, Department of Clinical and Experimental Medicine, ${ }^{4}$ Department of Human Pathology, University of Messina, Messina, Italy

\section{Introduction}

A 42-years old caucasian woman was admitted to our hospital because of jaundice developed some days earlier. Her history was positive for mixed connective tissue disease and autoimmune thrombocytopenia treated for several months with oral corticosteroids. At admission, a contrast-enhanced CT scan of the abdomen revealed an enlargement of the head of the pancreas, marked dilation of the main bile duct and moderately dilated intrahepatic bile ducts (figure 1). An endoscopic ultrasound guided fine needle aspiration (FNA) was performed; histology was negative for neoplastic cells and immunohistochemistry with positive staining for cytokeratin (CK)19, but negative staining for Insulin-like growth factor II mRNA-binding protein (IMP)-3 together with a low (MIB)-1 labelling index $(<2 \%)$ was consistent with an inflammatory process. Endoscopic retrograde cholangio pancreatography (ERCP) for biliary stenting was complicated by hemoperitoneum and the patient was transferred to the surgery unit

\section{Publication History:}

Received: June 11, 2014

Accepted: October 01, 2014

Published: October 03, 2014

\section{Keywords:}

CK 19, IMP3, FNA, IgG4, ANA, Complement

treated with Insulin

Several investigations including serum IgG4 and mutations of the cystic fibrosis transmembrane conductance regulator gene were negative. Autoimmunity testing revealed positivity for antinuclear antibodies (ANA) (1:160) and anti smooth muscle antibodies (ASMA) (1:80). Complement levels were low (C3: $76 \mathrm{mg} / \mathrm{dl}$ [normal levels: $90-180 \mathrm{mg} / \mathrm{dl}$ ]; C4: $9 \mathrm{mg} / \mathrm{dl}$ [normal levels:10-40 mg/dl]) and microscopic analysis of urines was positive for hyaline cylinders with

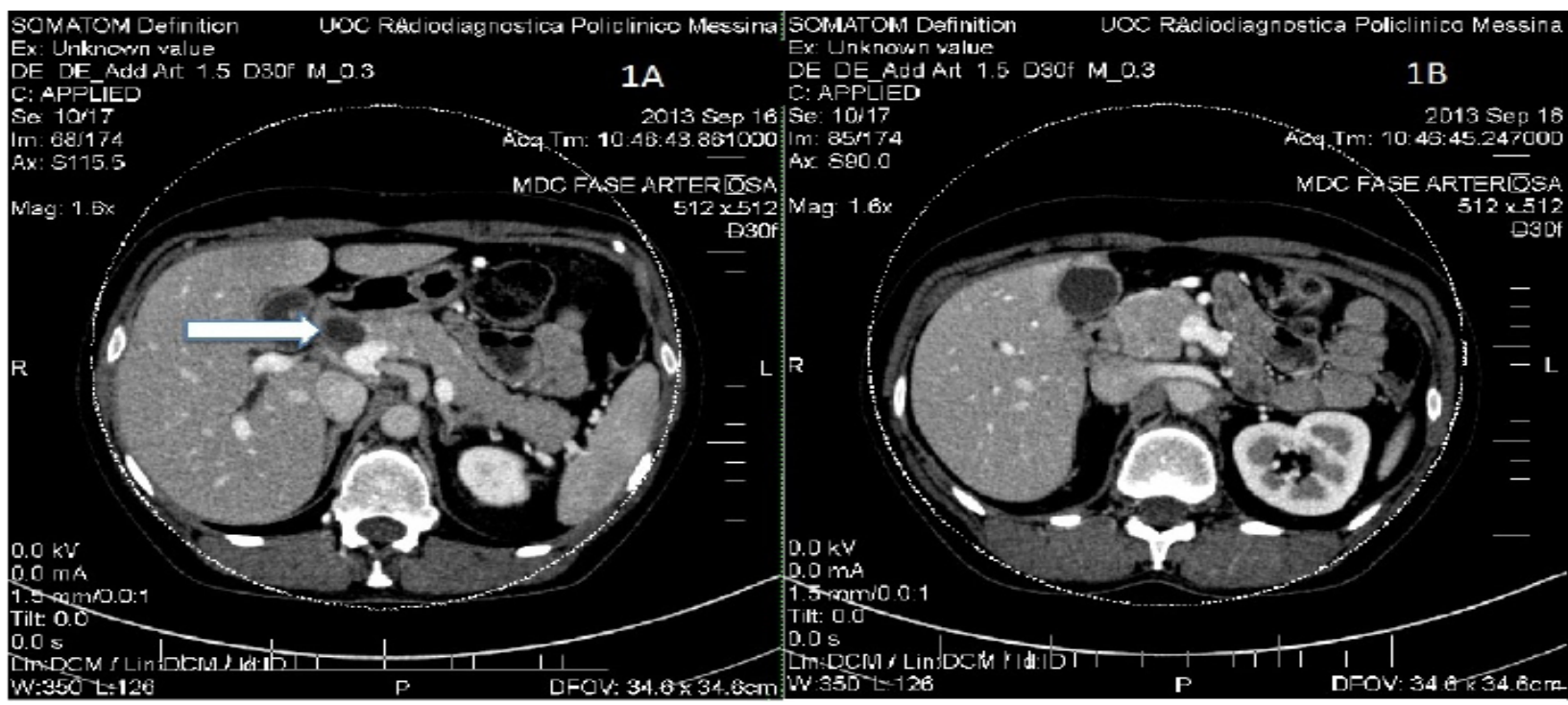

Figure 1: Contrast-enhanced CT scan at the moment of disease onset; A: the arrow indicates the dilated main bile duct, together with a normal appearance of the pancreas body and tail. B: the enlarged head of the pancreas immediately below the common bile duct showing no focal contrast enhancement.

and, subsequently, because of hemodynamic instability to the ICU. During recovery and resolution of jaundice a spontaneous free colonic perforation occurred and the patient underwent left-sided colectomy together with an ileostomy in the right hemi-abdomen. Histological evaluation of the surgical specimen was consistent with CMV infection. The patient slowly recovered and was discharged after three months. She was readmitted 1 month later because of malnutrition and dehydration; in this occasion a contrast-enhanced ultrasound (US) evaluation of the pancreas revealed no focal lesion and a globally moderately dilated main pancreatic duct consistent with chronic pancreatitis (figure 2). At this moment, repeated determination of blood glucose revealed diabetes mellitus that was
"Corresponding Author: Dr. Walter Fries, Clinical Unit for Chronic Bowel Disorders, Department of Clinical and Experimental Medicine, University of Messina, Messina, Italy; E-mail: fwalter@unime.it

Citation: Ardesia M, Cintolo M, Crinò S, Todaro P, Speciale G, et al. (2014) Acute onset of Lupus associated Pancreatitis Mimicking Pancreatic Cancer. Int J Gastroenterol Disord Ther 1: 107. doi: http://dx.doi.org/10.15344/2393 $8498 / 2014 / 107$

Copyright: (c) 2014 Ardesia et al. This is an open-access article distributed under the terms of the Creative Commons Attribution License, which permits unrestricted use, distribution, and reproduction in any medium, provided the original author and source are credited. 
Citation: Ardesia M, Cintolo M, Crinò S, Todaro P, Speciale G, et al. (2014) Acute onset of Lupus associated Pancreatitis Mimicking Pancreatic Cancer. Int J Gastroenterol Disord Ther 1: 107. DOI: http://dx.doi.org/10.15344/2393-8498/2014/107

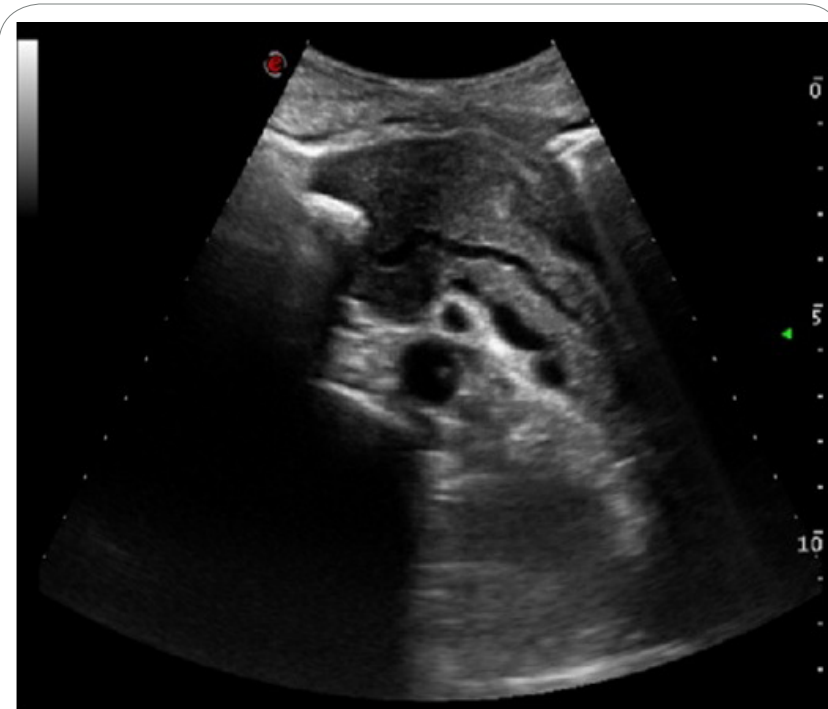

Figure 2: Ultrasound evaluation of the patient's pancreas 8 months after clinical onset of disease before administration of i.v. contrast.

a creatinine clearance of $77 \mathrm{ml} / \mathrm{min}$. The patient was stabilized and weight gain was obtained by introducing oral pancreatic enzyme supplementation with pancrelipase $150 \mathrm{mg}$ b.i.d. (10.000 units of lipase, 8000 units of amylase and 600 units of protease per tablet). Based on clinical, immunological and biochemical parameters the diagnosis of chronic lupus-associated pancreatitis was made and the patient was discharged on low-dose methylprednisolone.

\section{Discussion}

This is to the best of our knowledge the first description of a lupus-associated chronic pancreatitis mimicking pancreatic cancer. The modality of presentation with obstructive jaundice is frequently reported in type 1 autoimmune pancreatitis. Pancreatic ductal cancer was ruled out by means of the recently re-evaluated immunohistochemical markers for pancreatic neoplasia $[1,2]$ and autoimmune type 1 pancreatitis was excluded because of the absence of high serum IgG4 levels [3].

Chronic pancreatitis associated with systemic lupus erythematosus (SLE) is limited to a few case reports [4-7] and represents a rare finding. In an analysis on 136 patients with SLE,10 patients with clinical or subclinical pancreatitis were identified [8]. On logistic regression among the associated variables, thrombocytopenia as in our case, was identified. In the present case the diagnosis of SLE was made after the diagnosis of pancreatitis and was based on the recently revised criteria of the American College of Rheumatology (ACR), the Systemic Lupus International Collaboration Clinics (SLICC) criteria [9]. Diagnosis is based on the fulfillment of at least four criteria (out of seventeen) with at least one clinical criterion (in our patient: thrombocytopenia, hyaline cylinders in urines) and one immunologic criterion (in our patient: ANA positivity and low C3 and C4 levels). These new SLICC criteria were found ta have a greater sensitivity (94\%) and equal specificity (92\%) compared with the former revised criteria of the American College of Rheumatology [10].

Therapy of SLE is based on immunosuppressive drugs, first of all corticosteroids. This therapy was employed in our patient controlling thrombocytopenia. Long-term strategies with non-steroid regimens including rituximab are under evaluation.

\section{Conclusion}

In conclusion, we reported on a patient with autoimmune pathologies presenting with obstructive jaundice and an enlarged pancreatic head mimicking pancreatic cancer. After excluding pancreatic carcinoma, diagnosis converged on lupus-associated chronic pancreatitis.

\section{References}

1. Liu H, Shi J, Anandan V, Wang HL, Diehl D, Blansfield J, et al. (2012) Reevaluation and identification of the best immunohistochemical panel (pVHL, Maspin, S100P, IMP-3) for ductal adenocarcinoma of the pancreas. Arch Pathol Lab Med 136: 601-609.

2. Kloppel G, Adsay NV (2009) Chronic pancreatitis and the differential diagnosis versus pancreatic cancer. ArchPathol Lab Med. 133: 382-387.

3. Shimosegawa T, Chari ST, Frulloni L, Kamisawa T, Kawa S, et al. (2011) International consensus diagnostic criteria for autoimmune pancreatitis: guidelines of the International Association of Pancreatology. Pancreas 40:352-358.

4. Lariño Noia J, Macias Garcia F, Seijo Ríos S, Iglesias García J, Dominguez Muñoz JE (2009) Pancreatitis and systemic lupus erythematosus. Rev Esp Enferm Dig 101:571-579.

5. Borum M, Steimberg W, Steer M, Freedman S, White P (1993) Chronic pancreatitis: a complication of systemic lupus erythematosus. Gastroenterology 104: 613-615.

6. Hortas C, de las Heras G, Lopez-Arias MJ, Martin L, Pons-Romero F (1995) Chronic calcifying pancreatitis in rheumatic diseases. Ann Rheum Dis 54: 77-78.

7. Penalva JC, Martinez J, Pascual E, Palanca VM, Lluis F, et al. (2003) Chronic pancreatitis associated with systemic lupus erythematosus in a young girl. Pancreas 27: 275-277.

8. Medeiros MM, Fernandes GH, Pinto NS, Silveira VA. (2011) Clinical and subclinical pancreatitis in a cohort of patients diagnosed with systemic lupus erythematosus. Clin Exp Rheumatol 29: 776-782.

9. Petri M, Orbai AM, Alarcon GS, Gordon C, Merrill JT, et al. (2012) Derivation and validation of the Systemic Lupus International Collaborating Clinics classification criteria for systemic lupus erythematosus. Arthritis Rheum 64: 2677-2686.

10. Hochberg MC (1997) Updating the American College of Rheumatology revised criteria for the classification of systemic lupus erythematosus. ArthritisRheum 40:1725. 